\title{
Translation of c-Met Targeted Image-Guided Surgery Solutions in Oral Cavity Cancer-Initial Proof of Concept Data
}

\author{
Tessa Buckle ${ }^{1,2, *}$, Maarten van Alphen ${ }^{2} \mathbb{D}$, Matthias N. van Oosterom ${ }^{1,2} \mathbb{D}$, Florian van Beurden ${ }^{1}$, \\ Nina Heimburger ${ }^{1}$, Jaqueline E. van der Wal ${ }^{3}$, Michiel van den Brekel ${ }^{2}$, Fijs W. B. van Leeuwen ${ }^{1,2}$ \\ and Baris Karakullukcu ${ }^{2}$ (D)
}

check for updates

Citation: Buckle, T.; van Alphen, M.; van Oosterom, M.N.; van Beurden, F.; Heimburger, N.; van der Wal, J.E.; van den Brekel, M.; van Leeuwen, F.W.B.; Karakullukcu, B. Translation of c-Met Targeted Image-Guided Surgery Solutions in Oral Cavity Cancer-Initial Proof of Concept Data. Cancers 2021, 13, 2674. https: / / doi.org/10.3390/cancers13112674

Academic Editor: Juan P. Rodrigo

Received: 22 April 2021

Accepted: 27 May 2021

Published: 28 May 2021

Publisher's Note: MDPI stays neutral with regard to jurisdictional claims in published maps and institutional affiliations.

Copyright: (c) 2021 by the authors. Licensee MDPI, Basel, Switzerland. This article is an open access article distributed under the terms and conditions of the Creative Commons Attribution (CC BY) license (https:/ / creativecommons.org/licenses/by/ $4.0 /)$.
1 Interventional Molecular Imaging Laboratory, Department of Radiology, Leiden University Medical Center, 2333 ZA Leiden, The Netherlands; m.n.van_oosterom@lumc.nl (M.N.v.O.); f.van_beurden@lumc.nl (F.v.B.); n.heimburger@lumc.nl (N.H.); f.w.b.van_leeuwen@lumc.nl (F.W.B.v.L.)

2 Department of Head and Neck Surgery and Oncology, Netherlands Cancer Institute-Antoni van Leeuwenhoek Hospital, 1066 CX Amsterdam, The Netherlands; m.v.alphen@nki.nl (M.v.A.); m.v.brekel@nki.nl (M.v.d.B.); b.karakullukcu@nki.nl (B.K.)

3 Department of Pathology, Netherlands Cancer Institute-Antoni van Leeuwenhoek Hospital, 1066 CX Amsterdam, The Netherlands; j.vd.wal@nki.nl

* Correspondence: t.buckle@lumc.nl

Simple Summary: Translation of tumor-specific fluorescent tracers is crucial in the realization intraoperative of tumor identification during fluorescence-guided surgery. Ex vivo assessment of surgical specimens after topical tracer application has the potential to reveal the suitability of a potential surgical target prior to in vivo use in patients. In this study, the c-Met receptor was identified as a possible candidate for fluorescence-guided surgery in oral cavity cancer. Freshly excised tumor specimens obtained from ten patients with squamous cell carcinoma of the tongue were incubated with EMI-137 and imaged with a clinical-grade Cy5 prototype fluorescence camera. In total, 9/10 tumors were fluorescently illuminated, while non-visualization could be linked to nonsuperficial tumor localization. Immunohistochemistry revealed c-Met expression in all ten specimens. Tumor assessment was improved via video representation of the tumor-to-background ratio.

Abstract: Intraoperative tumor identification (extension/margins/metastases) via receptor-specific targeting is one of the ultimate promises of fluorescence-guided surgery. The translation of fluorescent tracers that enable tumor visualization forms a critical component in the realization of this approach. Ex vivo assessment of surgical specimens after topical tracer application could help provide an intermediate step between preclinical evaluation and first-in-human trials. Here, the suitability of the c-Met receptor as a potential surgical target in oral cavity cancer was explored via topical ex vivo application of the fluorescent tracer EMI-137. Freshly excised tumor specimens obtained from ten patients with squamous cell carcinoma of the tongue were incubated with EMI-137 and imaged with a clinical-grade Cy5 prototype fluorescence camera. In-house developed image processing software allowed video-rate assessment of the tumor-to-background ratio (TBR). Fluorescence imaging results were related to standard pathological evaluation and c-MET immunohistochemistry. After incubation with EMI-137, 9/10 tumors were fluorescently illuminated. Immunohistochemistry revealed c-Met expression in all ten specimens. Non-visualization could be linked to a more deeply situated lesion. Tumor assessment was improved via video representation of the TBR (median TBR: 2.5 (range 1.8-3.1)). Ex vivo evaluation of tumor specimens suggests that c-Met is a possible candidate for fluorescence-guided surgery in oral cavity cancer.

Keywords: molecular imaging; fluorescence; image-guided surgery; c-Met; head and neck cancer

\section{Introduction}

Fluorescence-guided applications in head-and-neck surgery are at the forefront of the progression realized in this field [1-4]. The most common fluorescence guidance applica- 
tions in head and neck surgery are implemented during the surgical resection of sentinel nodes, a secondary means of identifying metastatic tumor spread $[1,2,5,6]$. According to EANM guidelines for sentinel node localization in oral cavity cancer [7], imaging of lymphatic drainage pathways can provide both a preoperative roadmap as well as intraoperative guidance towards micro metastatic lesions in the part of the lymphatic system that is associated with the primary tumor. Technical (r)evolutions in (radio)pharmaceutical design and surgical imaging modalities have advanced sentinel node resection and have provided insight into the tracer doses required for surgical guidance [1,2]. The holy grail in image-guided surgery, however, is direct identification of the primary tumor (margins) and/or (macro)metastases. This is based on the assumption that, through the direct illumination of tumor cells, image guidance supports intraoperative tumor delineation [8] and could aid in the resection of lesions that could not be identified otherwise [9].

Although broadly explored in the preclinical setting [10,11], the application of tumorspecific tracers in clinical trials is still in its infancy. While clinical trials are performed using an increasing array of targets and matching fluorescence tracers, the epidermal growth factor receptor (EGFR) appears to be most widely studied [6,12-14]. Given the complexity of receptor over-expression and heterogeneity among head and neck cancers (e.g., melanoma and oral squamous cell carcinoma (OSCC)), one may wonder if the available number of tracer candidates should not be extended. Expansion of the arsenal of tracers seems to be limited by a translational gap between preclinical work in artificial tumor models and in vivo implementation in clinical trials. We, and others, have argued that receptor-targeting tracers can be evaluated using an ex vivo topical application setting first, using fresh surgical samples $[8,15]$. Such evaluations help circumvent the notoriously poor correlation between mRNA and protein expression and cytoplasmic target presence using immunohistochemistry (IHC; [16-18]). This approach, however, cannot solve the intricate pharmacokinetic challenges of tracer design that generally tend to focus on GMP-compatible synthesis, targeting affinity and biodistribution [19].

The role of the mesenchymal-epithelial transition factor (c-Met) in the progression of head and neck cancer is well described [20,21]. C-Met plays an important role in tumor development [20]. Furthermore, its over-expression is stated to be linked to poor pathological features and prognosis [21]. Immunohistochemical assessment of c-Met in squamous cell carcinoma (SCC), the most frequent form of cancer in the head and neck area, shows expression in $78 \%-82.9 \%$ of tumors [21-23]. In OSCC, c-Met overexpression is substantially higher than in normal mucosa located adjacent to the tumor [20]. Together with the multiple examples wherein c-Met is being exploited for therapeutic purposes [24], this implies that c-Met could also serve as an imaging target for OSCC. EMI-137 is a c-Met targeting fluorescent tracer that, following extensive tracer optimization and preclinical evaluations, has been translated to the clinic and comes with thoroughly documented pharmacokinetics [9]. This tracer also previously demonstrated its ability to apply c-Met targeted resection of colorectal polyps, Barret's neoplasia and penile cancer, based on far-red related fluorescence after intravenous administration $[8,9,25]$.

To address the need for rapid translation of tumor-targeted image-guided surgery solutions for oral cavity cancer, we explored c-Met as a potential surgical target in OSCC. These initial evaluations were based on ex vivo incubation of fresh surgical tongue tumor specimens with EMI-137 (Figure 1), which was subsequently imaged with a clinical-grade Cy5 prototype fluorescence camera system (Figure 2). 




Figure 1. Tumor incubation and illumination. Schematic overview of the workflow from tumor excision to illumination. After excision, the tongue tumor sample was incubated in a solution containing EMI-137. After washing to eliminate unbound tracer, fluorescence imaging allowed visualization of the tumor within the specimen.
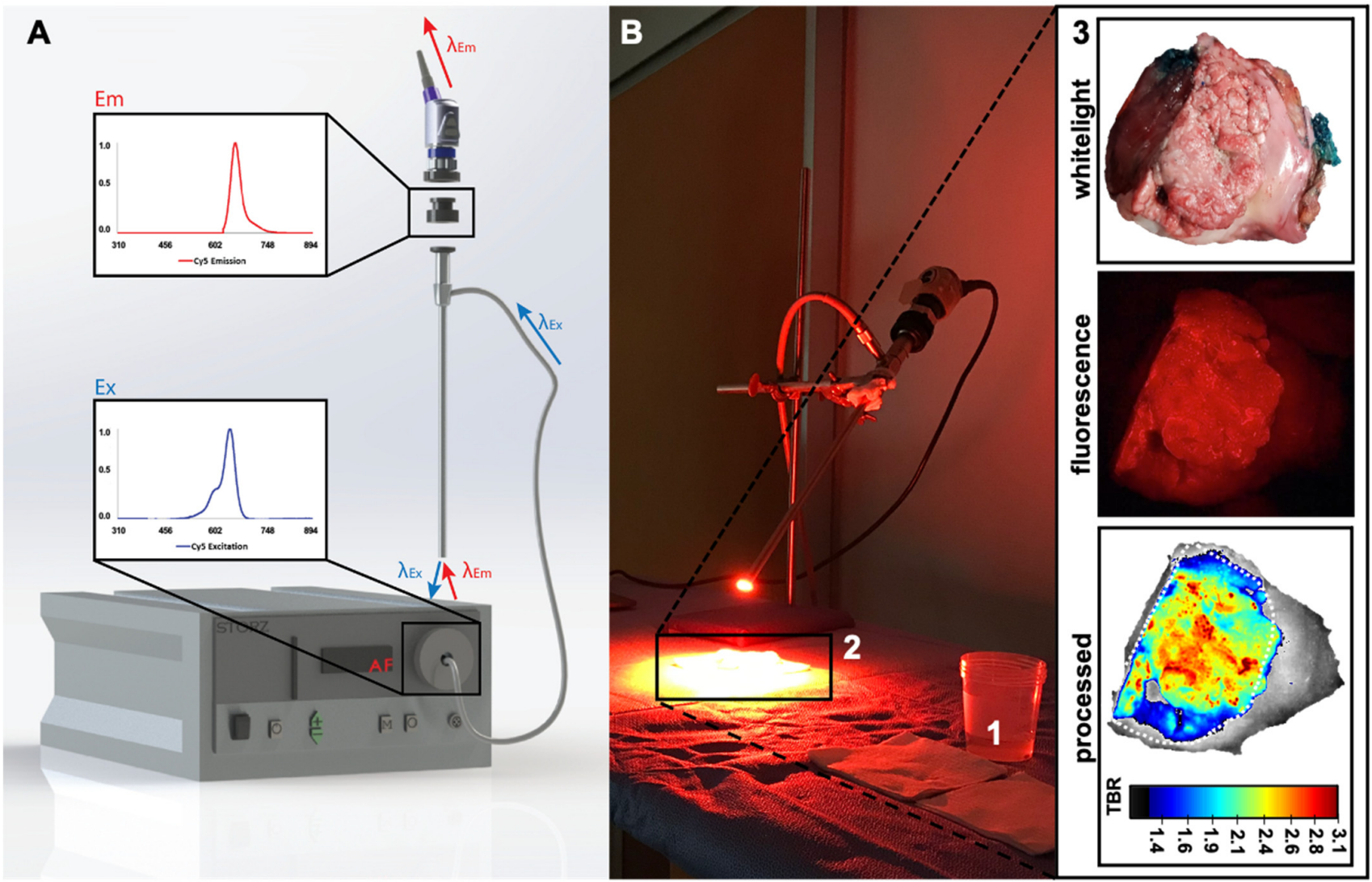

Figure 2. Imaging set-up and image processing. (A) The dedicated Cy5 imaging system consisting out of a Karl Storz light-source (I), fluorescence camera (II), Cy5 clip-on filter (III) and scope (IV). Inserts show the fluorescence excitation (bottom; $\lambda_{\mathrm{ex}} 650 \mathrm{~nm}$ ) and emission (top; $\lambda_{\mathrm{em}} 670 \mathrm{~nm}$ ) of the far-red dye Cy5. (B) Tracer incubation (1) and camera set-up for imaging of the tissue sample (2) of a representative tissue sample (3) showing the location of the tumor (dotted line) using white light (top) and standard fluorescence imaging (center) and after image processing (bottom; the scale bar represents the tumor-to-background ratio (TBR) corresponding to the fluorescence signal intensity).

\section{Materials and Methods}

\subsection{Patients}

Ten patients with OSCC of the tongue were prospectively included for ex vivo evaluation of the feasibility of c-Met-targeted tumor identification using fluorescence imaging. Primary tumor type, clinical TNM stage, tumor location, pathological TNM stage and 
differentiation grade were recorded. Approval for the study was obtained from the institutional review board, and all patients signed an informed consent that approved the use of excised tissue specimens for research purposes.

\subsection{Tracer Preparation}

For ex vivo sample assessment, the c-Met targeting Cy5 fluorescent tracer EMI-137 was dissolved in PBS to a concentration of $25,250,500$ or $2500 \mathrm{nmol}$ ( $20 \mathrm{~mL}$ per sample).

\subsection{Ex Vivo Incubation of Tissue and Fluorescence Imaging}

Resected tumor specimens were collected directly post-excision and bisected, and the fresh (non-fixed) samples were incubated with EMI-137 (Figure 1). Hereafter, samples were rinsed twice with PBS to clear unbound EMI-137, and the specimen was imaged directly after. The first three specimens were incubated in an increasing concentration of EMI-137. Rinsing and imaging were performed after each incubation step. The optimization of the imaging time was assessed by imaging at different intervals $(1,2$ and $5 \mathrm{~min})$ during incubation. The assessment of the most suitable concentration for incubation was performed based on fluorescence intensity and uptake in healthy tissue. The remaining samples were evaluated using the optimized protocol.

\subsection{Fluorescence Imaging}

White light and far-red fluorescence imaging were conducted using a clinical-grade Cy5 prototype (Karl Storz Endoskope $\mathrm{GmbH}$, Tuttlingen, Germany [26]; Figure 2A). This set-up was complemented with in-house developed image-processing software that allowed color-coding to be directly related to the tumor-to-background ratio (TBR; ratio between relative fluorescence units [27] in the tumor and surrounding tissue) via the creation of a rainbow colormap or heatmap. This heatmap allowed direct real-time visualization of the distribution of the fluorescence signal (pseudo-colored fluorescence overlay) within the tissue sample (visible on a separate screen) and representation of the TBR via an intensity-based scalebar (fluorescence signal intensity differences represented via a color spectrum; Figure 2(B3)). Image-processing software was written in C++-programming language using open-source computer vision libraries (OpenCV). Confirmation of the TBR values was obtained through manual assessment of the fluorescence images using ImageJ software (based on measurement of intensity in 10 different regions of interest throughout the sample, including tumor and surrounding tissue).

\subsection{Pathological Assessment}

After ex vivo imaging, the specimen was formalin-fixed, sectioned and then paraffinembedded. IHC of the formalin-fixed paraffin-embedded tumor samples was performed on a BenchMark Ultra autostainer (Ventana Medical Systems, Oro Valley, AZ, USA). In brief, $3 \mu \mathrm{m}$ paraffin sections were deparaffinized with the EZ prep solution (Ventana Medical Systems), and heat-induced antigen retrieval was carried out using Cell Conditioning 1 (Ventana Medical Systems). Hereafter, sections were incubated with an anti-c-MET antibody (clone SP44; Roche Diagnostics, Rotkreuz, Switserland), and an UltraView Universal DAB Detection Kit (Ventana Medical Systems) was used to visualize the c-Met expression. Slides were counterstained with Hematoxylin and Bluing Reagent (Ventana Medical Systems). Due to the lack of a quantitively read-out in routine immunohistochemistry, the c-Met expression levels were visually scored by a dedicated pathologist. Scoring was based on the intensity of the UltraView signal (four classifications were used: no staining, weak, moderate and strong, respectively,,,-++++++$)$. Both membrane and cytoplasmic staining were noted. Since c-Met is considered a membrane-bound biomarker [9], membranous staining was leading in the scoring. 


\section{Results}

\subsection{Patients}

Patient and tumor characteristics are presented in Table 1. Tumors were all located in the lateral tongue. Nine patients underwent removal of the primary tumor, and one patient underwent a re-excision. Clinical TNM stage ranged from T1 to T3 (T1: $N=5, \mathrm{~T} 2: N=4$ and T3: $N=1$ ).

Table 1. Patient characteristics.

\begin{tabular}{|c|c|c|c|c|c|c|c|c|}
\hline $\begin{array}{l}\text { Patient } \\
\text { No }\end{array}$ & Sex & Age & $\begin{array}{l}\text { Tumor } \\
\text { Type }\end{array}$ & $\begin{array}{l}\text { Clinical } \\
\text { T-Stage }\end{array}$ & $\begin{array}{c}\text { PA } \\
\text { T-Stage }\end{array}$ & $\begin{array}{l}\text { Fluorescence in Tumor } \\
\qquad(\mathrm{Y} / \mathrm{N})\end{array}$ & TBR & $\begin{array}{l}\text { c-Met } \\
\text { Status * }\end{array}$ \\
\hline 1 & M & 72 & OSCC & $\mathrm{T} 1$ & $\mathrm{~T} 1$ & $\mathrm{Y}$ & $1.8 \pm 0.3$ & + \\
\hline 2 & M & 62 & OSCC & T3 & $\mathrm{T} 2$ & $\mathrm{Y}$ & $2.5 \pm 0.7$ & $+/++$ \\
\hline 3 & M & 56 & OSCC & $\mathrm{T} 2$ & $\mathrm{~T} 2$ & $\mathrm{Y}$ & $2.0 \pm 0.1$ & $+/++$ \\
\hline 4 & $\mathrm{~F}$ & 86 & OSCC & $\mathrm{T} 1$ & $\mathrm{~T} 1$ & $\mathrm{Y}$ & $2.5 \pm 0.5$ & + \\
\hline 5 & $\mathrm{~F}$ & 80 & OSCC & $\mathrm{T} 2$ & $\mathrm{~T} 1$ & $\mathrm{Y}$ & $2.4 \pm 0.3$ & $++/+++$ \\
\hline 6 & $\mathrm{~F}$ & 67 & OSCC & $\mathrm{T} 2$ & $\mathrm{~T} 2$ & $\mathrm{Y}$ & $2.7 \pm 0.3$ & + \\
\hline 7 & M & 68 & OSCC & $\mathrm{T} 1$ & $\mathrm{~T} 1$ & $\mathrm{Y}$ & $3.1 \pm 0.7$ & $+/++$ \\
\hline 8 & $\mathrm{~F}$ & 68 & OSCC & $\mathrm{T} 2$ & $\mathrm{~T} 2$ & $\mathrm{Y}$ & $2.3 \pm 0.8$ & +++ \\
\hline 9 & $\mathrm{~F}$ & 76 & OSCC & $\mathrm{T} 1$ & $\mathrm{~T} 1$ & $\mathrm{~N}$ & N.A. & ++ \\
\hline 10 & M & 36 & OSCC & $\mathrm{T} 1$ & $\mathrm{~T} 1$ & $\mathrm{Y}$ & $2.5 \pm 0.5$ & $+/++$ \\
\hline
\end{tabular}

OSCC: oral squamous cell carcinoma. TBR: Tumor-to-background ratio. N.A.: Not available. No tumor detected; therefore, ratio fluorescence signal in tumor and surrounding healthy tissue could not be evaluated. ${ }^{*} \mathrm{C}$-Met status as identified on immunohistochemistry.

\section{Ex Vivo Incubation and c-Met Related Fluorescence Imaging}

During ex vivo assessment, the focus was placed on the primary tumor (Figure 1). Incubation of tissue specimens with different quantities of EMI-137 (25-2500 nmol) indicated that the best TBR was obtained using concentrations $\geq 250 \mathrm{nmol}$. Since incubation with $500 \mathrm{nmol}$ yielded the best TBR's, $500 \mathrm{nmol}$ was selected as the optimal concentration for incubation. Imaging at different time points during the incubation revealed that incubation time also had an impact. As the TBR's were highest after 5 min of incubation, this time point was used during further investigations.

After incubation with EMI-137 (Figures 1 and 2(B1)), a tumor-related fluorescence signal could be detected in 9/10 samples (Table 1, Figure 2(B3) and Figure 3A,B). Visual assessment of the one sample wherein the tumor could not be identified using fluorescence imaging revealed that there was no tumor present on the incubated cleavage plane (Figure 3C, white light image). Pathological assessment of this sample revealed tumor presence in less superficial areas in tissue sections that did not correspond with the incubated cleavage plane (Figure 3C, H\&E and c-Met staining).

Without processing, the Cy5-related fluorescence was presented as red-on-black (Figures 2B and 3). This allowed visualization of the uptake of EMI-137 in the sample. Real-time image processing using intensity-based rainbow color mapping enhanced the utility of these fluorescence images. This approach provided improved visual discrimination between tumor and healthy tissue, but the color-coded visualization also yields an intuitive rate interpretation of the TBR values (ranging from blue for low TBR to red for the highest TBR within the sample). The median TBR was 2.5 (range 1.8-3.1; Table 1), underlining the effective discrimination of the tumor from the surrounding tissue. The same visualization technique also provided improved insight into the heterogeneity within the lesion (Figures 2B and 3). Overall, expansion of fluorescence outside the primary tumor did not exceed TBR $>2$. 


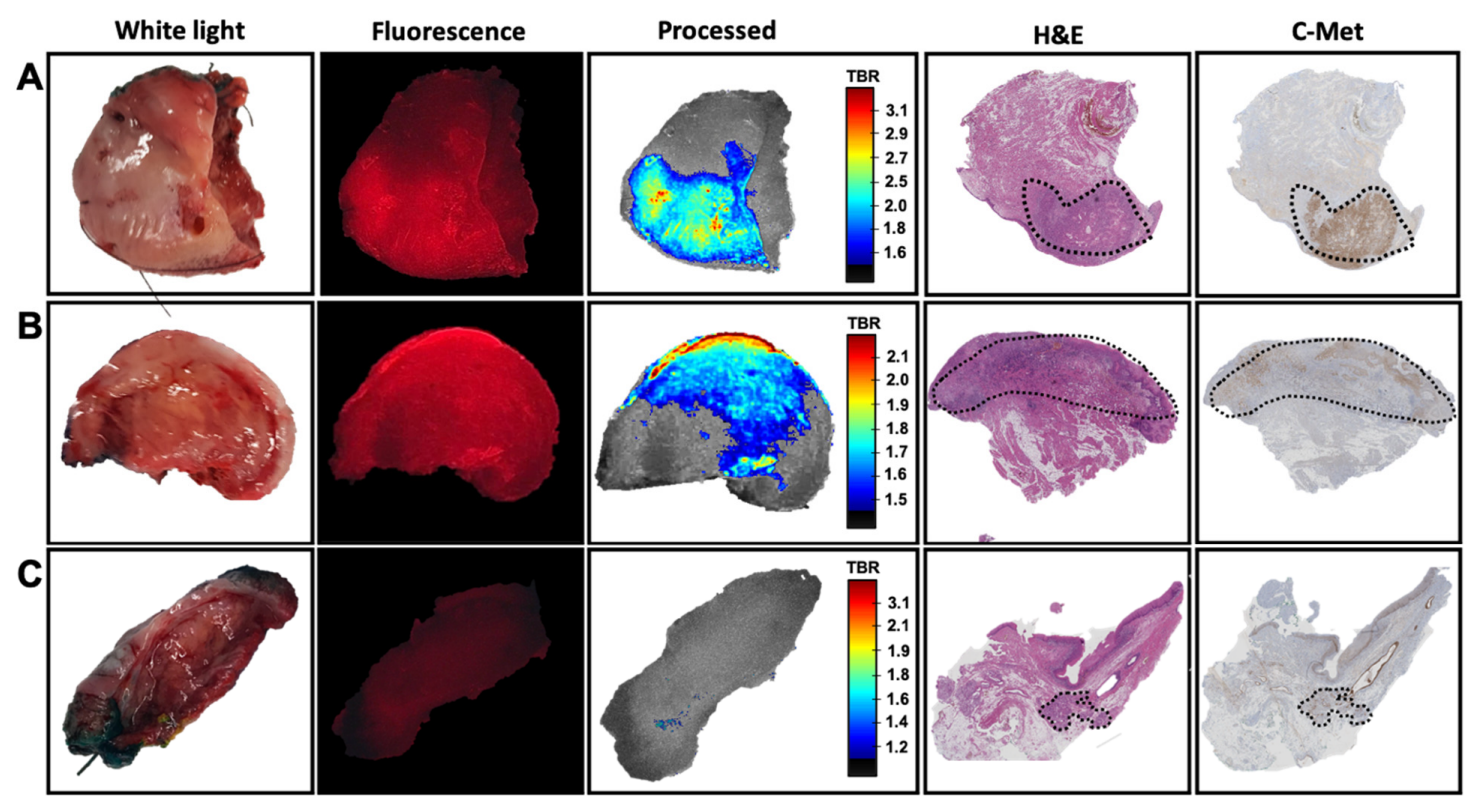

Figure 3. The correlation between c-Met targeted fluorescence and immunohistochemistry. Overview of imaging and pathological assessment of three different samples showing ex vivo white light, Cy5-based fluorescence imaging of the incubated tissue (fluorescence in red), real-time image processing of the fluorescence signal (including video representation of tumor-to-background ratio (TBR)), H\&E staining and c-MET immunohistochemistry. (A) superficial tumor localization, (B) tumor presence on the cleavage plane and (C) a sample without tumor presence on the cleavage plane. Delineation of the tumor (dashed) was based on H\&E.

The pathological assessment provided a TNM stage ranging between T1 and T2 (T1: $N=6$, T2: $N=4$; Table 1). The presence of EMI-137 in the tissue sample had no adverse effect on the further pathological assessment of the tissue. IHC revealed the expression of c-Met in 10/10 samples (Table 1) with a c-Met status ranging between + and +++ . The highest number of samples showed expression levels of $1+(3 / 10)$ or $1+/ 2+$ $(4 / 10)$. A clear overlap could be observed between the accumulation of EMI-137 and the c-Met expression levels identified using IHC (Figure 3). Furthermore, intensity differences seen in the fluorescence images could be correlated to heterogeneity in c-Met expression throughout the lesion and/or diffuse tumor presence throughout the tissue specimen. Here, it must be noted that some distortion between the fluorescence imaging on fresh tissue and the immunohistochemical analysis of fixates coupes was seen, which was caused by the deformation of the tissue during fixation. Unfortunately, the loss of a fluorescence signal in the embedded tissue samples (due to sample pre-treatment) meant that for fluorescence imaging, we needed to rely on the data obtained using the fresh tissue specimens. As a result, it becomes impossible to provide a direct overlay between fresh and fixed tissue samples. This limited our ability to finetune the scaling of the TBR visualization.

\section{Discussion}

Ex vivo assessment of fresh tissue samples obtained after oral cavity surgery provided the next step towards the realization of in vivo c-Met guided tumor surgery in the headand-neck area. This set-up successfully allowed the assessment of using c-Met as an imaging target in OSCC.

C-Met targeted fluorescence imaging, in combination with image processing, was shown to enable signal intensity-based identification in $90 \%$ of the primary tumor samples based on the representation of the TBR (Figures 2B and 3). However, c-Met expression was observed in all tumor specimens at IHC (Table 1). This mismatch seems to be caused by the non-superficial tumor localization on either the surface of the tongue or the cleavage plane (Figure 3C). Both fluorescence imaging and ex vivo tissue incubation can be impaired by tissue overlying the tumor. In the case of fluorescence imaging, it is well documented 
that tissue attenuates and scatters the fluorescence signal [26]. While for tissue incubation the maximum depth of tracer penetration is not yet well understood, there are studies that show that at least several cell layers (up to $300 \mu \mathrm{m}$ ) can be effectively stained and evaluated $[28,29]$. And while physics will dictate the superficial nature of fluorescence imaging, in vivo use of EMI-137 suggest that the issues behind tracer penetration in tissue are overcome when applying EMI-137 (or any other fluorescent tracer) in humans [8,9,25]. More specifically, in penile cancer patients, the presence of fluorescence was not limited to the rim of the tumor but could be detected throughout the tumor (tumor infiltration depth up to $24 \mathrm{~mm}$ [8]). This utility of EMI-137 is strengthened by other critical findings. For example, in colorectal cancer patients, EMI-137 allowed for the identification of lesions that were missed using white-light endoscopy [9]. Additionally important, the clinical implementation of EMI-137 fluorescence guidance did not interfere with the standard clinical surgical and pathological workflow of Barret's neoplasia and penile cancer $[8,25]$.

While the fluorescence signal is often presented using a pseudo-color (overlay) image [27], the standard procedure is to calculate the TBR at some point after the acquisition of the images. Real-time image processing not only provided increased discrimination between the tumor and surrounding tissue (Figures 2 and 3), but it also allowed assessment of fluorescence images to go from qualitative pseudo-colored fluorescence overlay images towards more quantitative analysis of the TBR in real-time. This improvement in signal representation also enabled assessment of the distribution of the fluorescence signal throughout the tissue sample, and thus the heterogeneity in c-Met expression. As real-time fluorescence imaging is said to enable improved decision making during tumor resection [27], real-time signal quantification (and representation) has the potential to further revolutionize its applicability. Obviously, scaling of the fluorescence images impacts image perception, and a clear cut-off point in the signal would help enables discrimination between the tumor and the surrounding tissue. Where some state that TBR values higher than the theoretical value of two are only of value, the human eye is sensitive enough to identify lower TBR values [27]. As such, setting a clinically relevant cut-off point for the fluorescent signal intensity is challenging to say the least.

According to the IUPAC regulations, the fluorescent emission used for surgery is classified into: visible fluorescence (400 nm-650 nm), far-red fluorescence (650 nm-780 nm) and NIR fluorescence (780-2000 nm [30]). While NIR-based fluorescence imaging is popular amongst many that pursue the development of new tracers for fluorescence-guided surgery, far-red Cy5-based tracers are also on the rise in clinical trials, e.g., based on EMI-137 [8,9,25] and cRGDY-PEG-Cy5.5-nanoparticles [6]. In fact, visible dyes, such as fluorescein and pPXi, have been widely applied in clinical trials [31]. Beyond that, literature even suggests that fluorescent emissions in different portions of the fluorescent spectrum can complement each other in multi-wavelength fluorescence imaging [26,31].

In the small sample size included in this study, c-Met expression was seen in all of the tumor samples, but lower percentages $(70 \%-78 \%)$ are reported in various tumor locations in the head and neck area [32-34]. An explanation for this discrepancy can be found in (1) differences in expression between tumors of different locations and variations that occur in c-Met expression during tumor progression and (2) variation in the standards used for interpretation of the immunohistochemical results due to the lack of a universally accepted scoring principle. With regard to the first, c-Met expression has been assessed in various tumor types in the head and neck (82.9\% in OSCC (exact location not specified; [33]), $70 \%$ in hypopharyngeal cancer [32] and 54.9\% in laryngeal carcinoma [35]). OSCC of the tongue (Table 1) has not been specifically assessed previously and could thus vary, similar to the variation seen in c-Met expression in different types of lung cancer (range $67-100 \%$ [36]). With regard to the second point, varying standards are used to determine the level of c-Met expression via immunohistochemistry, ranging from $>10 \%, 30 \%$ or $50 \%$ of cells to be stained before being deemed c-Met positive [22,32,37], while the use of a scoring system based on intensity categories as was used in this study is also not uncommon [32]. In addition, it is worth noting that cytoplasmic staining is often also 
included in the assessment of staining, while only membranous staining is in agreement with requirements for receptor-targeted imaging purposes [28].

In this study, the focus was placed on c-Met as an imaging target, whereas we are confident that the ex vivo set-up described can be applied in a more generic fashion, meaning for a wide range of targets, tumor types and fluorescent emissions. Besides revealing the potential of ex vivo tissue evaluation as an intermediate step in the translational process, this study clearly also has its limitations. One is the small sample size of this proof-of-concept study. The obvious next step is to corroborate these results in a larger group and in vivo. In penile cancer patients, the feasibility of in vivo targeting based on ex vivo tissue evaluation in a limited number of samples $(n=10)$ has been shown to allow successful translation of receptor-targeted imaging concepts [8]. Further investigations will also be focused on the possibility of setting TBR cut-off values and the identification of microscopic lesions via a more detailed assessment of the fluorescence uptake. Lastly, targeted approaches, such as c-Met targeting, may benefit from patient selection based on patient-specific characteristics. To this end, evaluation of the hypothesis that especially the patients with a worse tumor stage or human papillomavirus induced tumors might benefit from c-MET-targeted surgery [8] might be warranted, though further evaluation of the relation between the c-Met score, TBR and the T-stage and metastatic potential.

\section{Conclusions}

Ex vivo evaluation of tongue tumor specimens suggests that c-Met is a potential candidate target for fluorescence-guided surgery in oral squamous cell cancer/oral cavity cancer.

Author Contributions: Conceptualization, T.B., F.W.B.v.L. and B.K.; methodology, T.B.; software, M.N.v.O.; validation, T.B., M.v.A., M.N.v.O., J.E.v.d.W., F.W.B.v.L. and B.K.; formal analysis, T.B., M.v.A., M.N.v.O. and J.E.v.d.W.; investigation, T.B., M.v.A., M.N.v.O., F.v.B. and N.H.; resources, M.v.d.B., F.W.B.v.L. and B.K.; data curation, T.B., M.v.A., M.N.v.O., F.v.B. and N.H.; writing—original draft preparation, T.B. and F.W.B.v.L.; writing-review and editing, T.B., M.v.A., M.N.v.O., J.E.v.d.W., F.W.B.v.L. and B.K.; supervision, T.B., M.v.d.B., F.W.B.v.L. and B.K.; project administration, T.B., M.v.A., F.v.B., N.H. and B.K.; funding acquisition, F.W.B.v.L. All authors have read and agreed to the published version of the manuscript.

Funding: This research was financially supported by a Netherlands Organization for Scientific Research TTW-VICI grant (Grant No. TTW 16141). EMI-137 was provided by Edinburgh Molecular Imaging (EMI), and Karl Storz Endoskope GmbH provided the Cy5 fluorescence camera.

Institutional Review Board Statement: Ethical review was waived for this study, as participants were not subjected to in vivo additional/investigational procedures. Internal approval was obtained from the institutional review board of the NKI-AvL for the use of excised tissue for research purposes.

Informed Consent Statement: Informed consent for the use of tissue for research purposes was obtained from all subjects involved in the study.

Data Availability Statement: Data can be made available upon reasonable request.

Acknowledgments: We would like to thank Sven van Leeuwen and Imke Boekestijn for their assistance with figure creation. We also acknowledge the NKI-AVL Core Facility Molecular Pathology and Biobanking (CFMPB) for lab support.

Conflicts of Interest: The authors declare no conflict of interest. The funders had no role in the design of the study; in the collection, analyses, or interpretation of data; in the writing of the manuscript, or in the decision to publish the results.

\section{References}

1. Berger, D.; van den Berg, N.; van der Noort, V.; van der Hiel, B.; Valdés Olmos, R.A.; Buckle, T.A.; KleinJan, G.; Brouwer, O.R.; Vermeeren, L.; Karakullukçu, B.; et al. Technological (R)evolution leads to detection of more sentinel nodes in patients with melanoma in the head and neck region. J. Nucl. Med. 2021. [CrossRef]

2. KleinJan, G.H.; Bunschoten, A.; van den Berg, N.S.; Olmos, R.A.; Klop, W.M.; Horenblas, S.; Van Der Poel, H.G.; Wester, H.-J.; Van Leeuwen, F.W.B. Fluorescence guided surgery and tracer-dose, fact or fiction? Eur. J. Nucl. Med. Mol. Imaging 2016, 43, 1857-1867. [CrossRef] 
3. Lee, Y.J.; Krishnan, G.; Nishio, N.; van den Berg, N.S.; Lu, G.; Martin, B.A.; van Keulen, S.; Colevas, A.D.; Kapoor, S.; Liu, J.T.; et al. Intraoperative fluorescence-guided surgery in head and neck squamous cell carcinoma. Laryngoscope 2021, 131, 529-534. [CrossRef] [PubMed]

4. Vonk, J.; de Wit, J.G.; Voskuil, F.J.; Witjes, M.J.H. Improving oral cavity cancer diagnosis and treatment with fluorescence molecular imaging. Oral Dis. 2021, 27, 21-26. [CrossRef]

5. Christensen, A.; Juhl, K.; Kiss, K.; Lelkaitis, G.; Charabi, B.W.; Mortensen, J.; Kjær, A.; Von Buchwald, C. Near-infrared fluorescence imaging improves the nodal yield in neck dissection in oral cavity cancer-A randomized study. Eur. J. Surg. Oncol. 2019, 45, 2151-2158. [CrossRef] [PubMed]

6. Zanoni, D.K.; Stambuk, H.E.; Madajewski, B.; Montero, P.H.; Matsuura, D.; Busam, K.J.; Ma, K.; Turker, M.Z.; Sequeira, S.; Gonen, M.; et al. Use of ultrasmall core-shell fluorescent silica nanoparticles for image-guided sentinel lymph node biopsy in head and neck melanoma: A nonrandomized clinical trial. JAMA Netw. Open 2021, 4, e211936. [CrossRef]

7. Giammarile, F.; Schilling, C.; Gnanasegaran, G.; Bal, C.; Oyen, W.J.G.; Rubello, D.; Schwarz, T.; Tartaglione, G.; Miller, R.N.; Paez, D.; et al. The EANM practical guidelines for sentinel lymph node localisation in oral cavity squamous cell carcinoma. Eur. J. Nucl. Med. Mol. Imaging 2019, 46, 623-637. [CrossRef]

8. De Vries, H.M.B.; Bekers, E.; van Oosterom, M.N.; Karakullukcu, M.B.; van der Poel, H.G.; van Leeuwen, F.W.B.; Buckle, T. Brouwer, O.R. c-MET receptor-targeted fluorescence-guided surgery-First experience in penile squamous cell carcinoma patients, a phase IIa study. J. Nucl. Med. 2021. [CrossRef] [PubMed]

9. Burggraaf, J.; Kamerling, I.M.; Gordon, P.B.; Schrier, L.; de Kam, M.L.; Kales, A.J.; Bendiksen, R.; Indrevoll, B.; Bjerke, R.M.; Moestue, S.A.; et al. Detection of colorectal polyps in humans using an intravenously administered fluorescent peptide targeted against c-Met. Nat. Med. 2015, 21, 955-961. [CrossRef]

10. Debie, P.; Hernot, S. Emerging fluorescent molecular tracers to guide intra-operative surgical decision-making. Front. Pharmacol. 2019, 10, 510. [CrossRef]

11. Joshi, B.P.; Wang, T.D. Targeted optical imaging agents in cancer: Focus on clinical applications. Contrast Media Mol. Imaging 2018, 2018, 2015237. [CrossRef]

12. Hernot, S.; van Manen, L.; Debie, P.; Mieog, J.S.D.; Vahrmeijer, A.L. Latest developments in molecular tracers for fluorescence image-guided cancer surgery. Lancet Oncol. 2019, 20, e354-e367. [CrossRef]

13. Lauwerends, L.J.; van Driel, P.; Baatenburg de Jong, R.J.; Hardillo, J.A.U.; Koljenovic, S.; Puppels, G.; Mezzanotte, L.; Löwik, C.W.G.M.; Rosenthal, E.L.; Vahrmeijer, A.L.; et al. Real-time fluorescence imaging in intraoperative decision making for cancer surgery. Lancet Oncol. 2021. [CrossRef]

14. Voskuil, F.J.; Steinkamp, P.J.; Zhao, T.; van der Vegt, B.; Koller, M.; Doff, J.J.; Jayalakshmi, Y.; Hartung, J.P.; Gao, J.; Sumer, B.D.; et al. Exploiting metabolic acidosis in solid cancers using a tumor-agnostic $\mathrm{pH}$-activatable nanoprobe for fluorescence-guided surgery. Nat. Commun. 2020, 11, 3257. [CrossRef] [PubMed]

15. Elekonawo, F.M.K.; de Gooyer, J.M.; Bos, D.L.; Goldenberg, D.M.; Boerman, O.C.; Brosens, L.A.A.; Bremers, A.J.; De Wilt, J.H.; Rijpkema, M. Ex vivo assessment of tumor-targeting fluorescent tracers for image-guided surgery. Cancers 2020, 12, 987. [CrossRef]

16. Kuil, J.; Buckle, T.; van Leeuwen, F.W. Imaging agents for the chemokine receptor 4 (CXCR4). Chem. Soc. Rev. 2012, 41, 5239-5261. [CrossRef] [PubMed]

17. Koussounadis, A.; Langdon, S.P.; Um, I.H.; Harrison, D.J.; Smith, V.A. Relationship between differentially expressed mRNA and mRNA-protein correlations in a xenograft model system. Sci. Rep. 2015, 5, 10775. [CrossRef]

18. Taquet, N.; Dumont, S.; Vonesch, J.L.; Hentsch, D.; Reimund, J.M.; Muller, C.D. Differential between protein and mRNA expression of CCR7 and SSTR5 receptors in Crohn's disease patients. Mediat. Inflamm. 2009, 2009, 285812. [CrossRef]

19. Van Leeuwen, F.W.B.; Cornelissen, B.; Caobelli, F.; Evangelista, L.; Rbahvidal, L.; Del Vechhio, S.; Xavier, C.; Bardet, J.; Hendriks de Jong, M. Genaration of fluorescently labeled tracers-Which features influence the translational potential? EJNMMI Radiopharm. Chem. 2017, 2, 15. [CrossRef]

20. Sun, Z.; Liu, Q.; Ye, D.; Ye, K.; Yang, Z.; Li, D. Role of c-Met in the progression of human oral squamous cell carcinoma and its potential as a therapeutic target. Oncol. Rep. 2018, 39, 209-216. [CrossRef]

21. Kim, J.H.; Kim, B.J.; Kim, H.S. Clinicopathological impacts of high c-Met expression in head and neck squamous cell carcinoma: A meta-analysis and review. Oncotarget 2017, 8, 113120-113128. [CrossRef]

22. Freudlsperger, C.; Alexander, D.; Reinert, S.; Hoffmann, J. Prognostic value of c-Met expression in oral squamous cell carcinoma. Exp. Ther. Med. 2010, 1, 69-72. [CrossRef]

23. Lo Muzio, L.; Farina, A.; Rubini, C.; Coccia, E.; Capogreco, M.; Colella, G.; Leonardi, R.; Campisi, G.; Carinci, F. Effect of c-Met expression on survival in head and neck squamous cell carcinoma. Tumor Biol. 2006, 27, 115-121. [CrossRef] [PubMed]

24. Huang, X.; Li, E.; Shen, H.; Wang, X.; Tang, T.; Zhang, X.; Tang, Z.; Guo, C.; Bai, X.; Liang, T. Targeting the HGF/MET axis in cancer therapy: Challenges in resistance and opportunities for improvement. Front. Cell Dev. Biol. 2020, 8, 150. [CrossRef]

25. De Jongh, S.J.; Voskuil, F.J.; Schmidt, I.; Karrenbeld, A.; Kats-Ugurlu, G.; Meersma, G.J.; Westerhof, J.; Witjes, M.J.H.; van Dam, G.M.; Robinson, D.J.; et al. C-Met targeted fluorescence molecular endoscopy in Barrett's esophagus patients and identification of outcome parameters for phase-I studies. Theranostics 2020, 10, 5357-5367. [CrossRef] [PubMed]

26. Van Willigen, D.M.; van den Berg, N.S.; Buckle, T.; KleinJan, G.H.; Hardwick, J.C.; van der Poel, H.G.; Van Leeuwen, F.W. Multispectral fluorescence guided surgery; a feasibility study in a phantom using a clinical-grade laparoscopic camera system. Am. J. Nucl. Med. Mol. Imaging 2017, 7, 138-147. [PubMed] 
27. Tummers, W.S.; Warram, J.M.; van den Berg, N.S.; Miller, S.E.; Swijnenburg, R.J.; Vahrmeijer, A.L.; Rosenthal, E.L. Recommendations for reporting on emerging optical imaging agents to promote clinical approval. Theranostics 2018, 8, 5336-5347. [CrossRef] [PubMed]

28. Buckle, T.; Kuil, J.; van den Berg, N.S.; Bunschoten, A.; Lamb, H.J.; Yuan, H.; Josephson, L.; Jonkers, J.; Borowsky, A.D.; Van Leeuwen, F.W.B. Use of a single hybrid imaging agent for integration of target validation with in vivo and ex vivo imaging of mouse tumor lesions resembling human DCIS. PLoS ONE 2013, 8, e48324. [CrossRef]

29. Crosignani, V.; Dvornikov, A.; Aguilar, J.S.; Stringari, C.; Edwards, R.; Mantulin, W.W.; Gratton, E. Deep tissue fluorescence imaging and in vivo biological applications. J. Biomed. Opt. 2012, 17, 116023. [CrossRef]

30. Van Leeuwen, F.W.; Hardwick, J.C.; van Erkel, A.R. Luminescence-based imaging approaches in the field of interventional molecular imaging. Radiology 2015, 276, 12-29. [CrossRef]

31. Van Beurden, F.; van Willigen, D.M.; Vojnovic, B.; van Oosterom, M.N.; Brouwer, O.R.; der Poel, H.G.V.; Kobayashi, H.; van Leeuwen, F.W.B.; Buckle, T. Multi-wavelength fluorescence in image-guided surgery, clinical feasibility and future perspectives. Mol. Imaging 2020, 19, 1536012120962333. [CrossRef]

32. Kim, C.-H.; Moon, S.-K.; Bae, J.-H.; Ho Lee, J.; Ho Han, J.; Kim, K.; Choi, E.C. Expression of hepatocyte growth factor and c-Met in hypopharyngeal squamous cell carcinoma. Acta Oto-Laryngol. 2006, 126, 88-94. [CrossRef]

33. Lo Muzio, L.; Leonardi, R.; Mignogna, M.D.; Pannone, G.; Rubini, C.; Pieramici, T.; Trevisiol, L.; Ferrari, F.; Serpico, R.; Testa, N.; et al. Scatter factor receptor (c-Met) as possible prognostic factor in patients with oral squamous cell carcinoma. Anticancer Res. 2004, 24, 1063-1069.

34. Marshall, D.D.; Rornberg, L.J. Overexpression of scatter factor and its receptor (c-met) in oral squamous cell carcinoma. Laryngoscope 1998, 108, 1413-1417. [CrossRef] [PubMed]

35. Sawatsubashi, M.; Sasatomi, E.; Mizokami, H.; Tokunaga, O.; Shin, T. Expression of c-Met in laryngeal carcinoma. Virchows Arch 1998, 432, 331-335. [CrossRef] [PubMed]

36. Ma, P.C.; Jagadeeswaran, R.; Jagadeesh, S.; Tretiakova, M.S.; Nallasura, V.; Fox, E.A.; Hansen, M.; Schaefer, E.; Naoki, K.; Lader, A.; et al. Functional expression and mutations of c-Met and its therapeutic inhibition with SU11274 and small interfering RNA in non-small cell lung cancer. Cancer Res. 2005, 65, 1479-1488. [CrossRef] [PubMed]

37. Nakajima, M.; Sawada, H.; Yamada, Y.; Watanabe, A.; Tatsumi, M.; Yamashita, J.; Matsuda, M.; Sakaguchi, T.; Hirao, T.; Nakano, $\mathrm{H}$. The prognostic significance of amplification and overexpression of c-met and c-erb B-2 in human gastric carcinomas. Cancer 1999, 85, 1894-1902. [CrossRef] 